\title{
Photocoagulation of disciform macular lesions with krypton laser
}

\author{
A. C. BIRD AND R. H. B. GREY \\ From the Institute of Ophthalmology, Moorfields Eye Hospital, City Road, London EC1V 2PD
}

SUMmARY Ten vascular disciform macular lesions were treated by krypton laser photocoagulation. In 8 the lesion resolved after therapy, and in 7 the retina remained flat for 6 months. On those patients treated successfully 6 had a visual acuity of $6 / 12$ or better. The morphology of the laser lesion differed from that of the argon lesion in that there is no evidence of thermal coagulation of the inner retina near the foveola.

Successful treatment of vascular disciform lesions using photocoagulation has been documented by several authors (Gass, 1971, 1973; Schatz and Patz, 1973a; Bird, 1974), but it is clear from these reports that a significant proportion $(25-50 \%)$ fail to respond to therapy. Moreover, some patients with obliteration of the subretinal neovascular tissue following treatment have poor residual visual acuity. The chances of therapeutic neovascular tissue ablation are less and the visual outcome is worse when the neovascular tissue, and therefore the required photocoagulation, is close to the foveola (Bird, 1974). Most of these observations concern the use of argon laser energy, and it has been suggested that the limitations of this form of energy may be related, at least in part, to the absorption of the green light $(488$ and $514.5 \mathrm{~nm})$ by luteal pigment (Marshall et al., 1974, 1975). Intraretinal absorption of energy will prevent delivery of energy to the subretinal tissues, may denervate the foveola, and may increase the risk of intraretinal fibrosis.

This paper reports initial experiences with the longer wavelength light of a krypton laser $(641 \mathrm{~nm})$ in the treatment of disciform macular lesions.

\section{Patients and methods}

Ten patients with vascular disciform lesions in which there was a discernible gap between the neovascular tissue and the foveola as shown by fluorescein angiography were selected for treatment by krypton laser photocoagulation (Table 1). Nine patients were over 60 years old and had diffuse age-related fundus disease in the eye to be treated and all but 1 (case 8 ) had a disciform lesion in the

Correspondence to Professor Bird.
Table 1 Morphological and visual outcome in patients treated with argon laser photocoagulation

\begin{tabular}{|c|c|c|c|c|c|c|}
\hline \multirow[b]{2}{*}{ Case } & \multirow[b]{2}{*}{$\begin{array}{l}\text { Age } \\
(y r)\end{array}$} & \multicolumn{2}{|c|}{ Visual acuity } & \multirow[b]{2}{*}{ Outcome } & \multirow[b]{2}{*}{$\begin{array}{l}\text { Proximity } \\
\text { (microns) }\end{array}$} & \multirow[b]{2}{*}{$\begin{array}{l}\text { Power } \\
\text { (milli- } \\
\text { watts) }\end{array}$} \\
\hline & & $\begin{array}{l}\text { Before } \\
\text { treatment }\end{array}$ & $\begin{array}{l}6 \text { months } \\
\text { after } \\
\text { treatment }\end{array}$ & & & \\
\hline 1 & 68 & $6 / 18$ & $6 / 12$ & Flat & 300 & 500 \\
\hline 2 & 73 & $6 / 9$ & $6 / 9$ & Flat & 400 & 500 \\
\hline 3 & 79 & $6 / 18$ & $6 / 12$ & Flat & 400 & 600 \\
\hline 4 & 70 & $6 / 18$ & CF & DD & 250 & 500 \\
\hline 5 & 73 & $6 / 24$ & $\mathrm{CF}$ & DD & 100 & 500 \\
\hline 6 & 71 & $6 / 12$ & $6 / 12$ & Flat & 300 & 750 \\
\hline 7 & 85 & $6 / 9$ & $6 / 9$ & Flat & 200 & 500 \\
\hline 8 & 76 & $6 / 9$ & CF & DD & 300 & 550 \\
\hline 9 & 68 & $6 / 12$ & $6 / 12$ & Flat & 250 & 450 \\
\hline 10 & 31 & $6 / 18$ & $6 / 36$ & Flat & 200 & 300 \\
\hline
\end{tabular}

$\mathrm{DD}=$ disciform lesion at 6 months after treatment. Proximity $=$ proximity of subretinal neovascular tissue to the foveola. Power= power in milliwatts of krypton laser beam. $\mathrm{CF}=$ counting fingers.

other. One patient was young, had presumed ocular histoplasma syndrome, and the other eye had good vision (case 10).

\section{MANAGEMENT TECHNIQUE}

In all patients the gap between the neovascular tissue and the foveola was measured by using a grid over the negative of the fluorescein angiogram (Gregor et al., 1977). Coagulation was undertaken with Lasertek krypton laser $(647 \mathrm{~nm})$ with sufficient power to produce intense coagulation; a $200 \mu \mathrm{m}$ aperture was used in each case and exposure time 

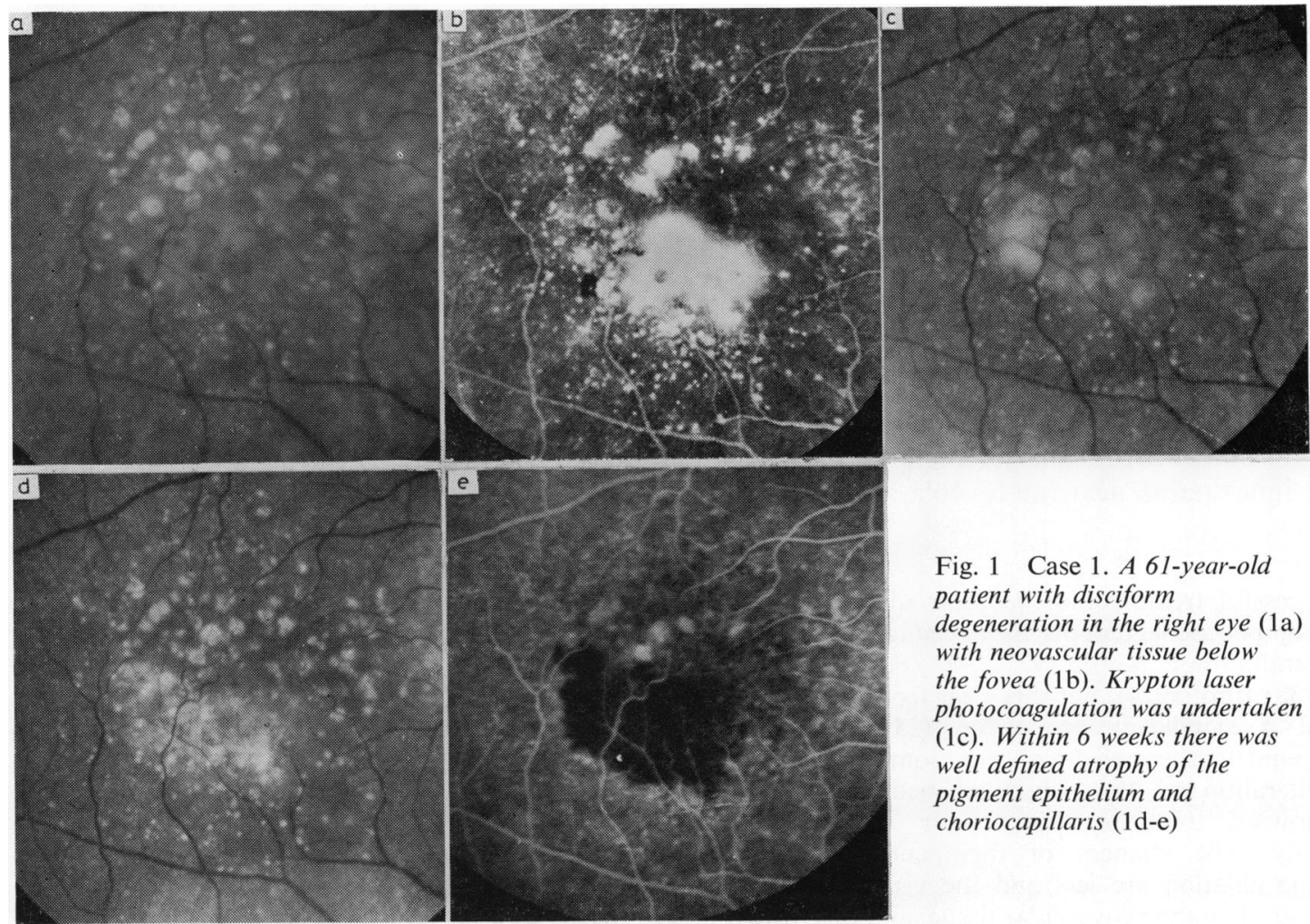

Fig. 1 Case 1. A 61-year-old patient with disciform

degeneration in the right eye (1a) with neovascular tissue below the fovea (1b). Krypton laser photocoagulation was undertaken (1c). Within 6 weeks there was well defined atrophy of the pigment epithelium and choriocapillaris (1d-e)

was 0.2 to 0.5 second. Coagulation was contiguous over the whole lesion and for at least $100 \mu \mathrm{m}$ beyond the limit of the neovascular tissue. One patient was treated twice (case 1) and the rest once. The progress of the lesion was reviewed at regular intervals by fluorescein angiography for at least 6 months after therapy.

\section{Results}

Of the 10 lesions treated, 7 became flat after photocoagulation and remained so for 6 months, 1 became flat but there was recurrent growth of new vessels 4 months after initial therapy (case 4), and in 2 there was recurrent growth of neovascular tissue immediately after photocoagulation (see Table 1). Of those patients successfully treated 6 retained or regained an acuity of $6 / 12$ or better.

During therapy the photocoagulation lesions appeared to be confined to the deep retina and pigment epithelium however close to the fovea the lesions were placed (Figs. 1 and 2). Even some distance from the fovea the lesions appeared to affect less of the retinal thickness than occurs with argon, giving the impression of a lighter burn (Figs. 1 and
2). It was also possible to obtain coagulations beneath parafoveal blood vessels by directing the beam through the blood vessels without uptake of energy in the inner retina or alteration of vessel calibre.

During the postoperative period choroidal and pigment atrophy occurred early (Figs. 1 and 3); infarction of retina due to vascular occlusion and intraretinal fibrosis was not seen during the period of review. In all the postphotocoagulation angiograms the site of treatment appeared dark, however long after therapy the angiogram was undertaken. At no stage was there hyperfluorescence due to transmission defect, though the large choroidal blood vessels were sometimes outlined in the outer layers of the lesions (Fig. 3).

\section{Discussion}

The differences between the parafoveal lesions produced by argon ( 488 and $514.5 \mathrm{~nm})$ and krypton $(647 \mathrm{~nm})$ wavelengths, which might have been predicted from theoretical data and from histological studies (Marshall and Bird, 1979), were evident clinically. It is the universal experience of 
Fig. 2 Case 8. A 76-year-old woman with a disciform lesion in the right eye (2a) with neovascular tissue below and temporal to the fovea (2b).

Krypton laser photocoagulation was undertaken $(2 \mathrm{c})$, and within 4 weeks the neovascular tissue appeared to be obliterated (2d)

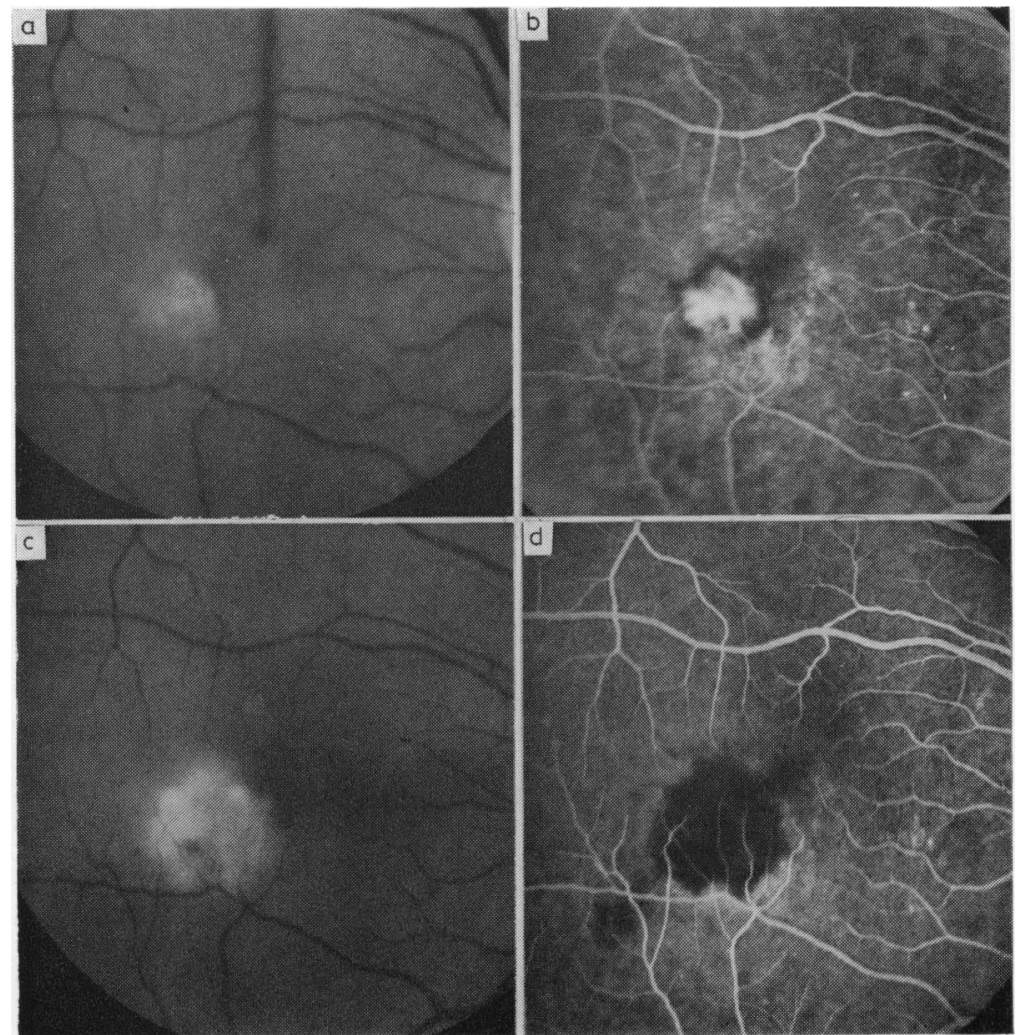

therapists using argon laser energy that while approaching the fovea there is a sudden change in the morphology of the photocoagulation lesion. Away from the fovea the lesions are confined to the outer retina, but uptake by the inner retina near the fovea causes dense white swelling of the inner retina, obscuring the view of the subretinal structures. The fact that the inner retinal lesion is often larger than those at the retinal pigment epithelium, and that the site at which the change takes place is unpredictable, compounds the hazard of this phenomenon. By contrast, with krypton laser energy it is possible to approach the fovea slowly, expanding the lesion centrally in a controlled fashion, and the responses appear to be much more predictable. Thus the therapy itself was easier to deliver and control with the krypton than with the argon laser.

The manifest differences between the lesions produced by the 2 lasers as seen clinically are confirmed by histological studies (Marshall and Bird, 1979) and can be accounted for by the differential absorption of the 2 wavelengths by luteal pigment. On a theoretical basis it could be argued that krypton may have advantages over argon laser photocoagulation in the treatment of macular disciform lesions. If the failure of argon laser treatment of juxtafoveal lesions is due to inner retinal absorption of energy and consequent failure of energy delivery to subretinal structures, the longer wavelength of krypton would be a better therapeutic agent. Similarly, if destruction of parafoveolar receptors and bipolar cells which subserve foveolar function prejudices the visual outcome following argon laser photocoagulation, this problem would be obviated by using krypton. Furthermore, in some patients a poor visual outcome with the argon laser can be attributed to occlusion of macular venules and arterioles due to absorption of energy by the blood vessel. Such an accident would also be avoided with krypton. Finally in certain cases poor visual acuity following apparently successful treatment of a disciform lesion can be attributed to intraretinal fibrosis and gross distortion of the fovea. If this is due to inner retinal absorption of energy with or without vascular occlusion, a better postoperative visual acuity would be expected after krypton than after argon laser photocoagulation.

During the 6-month period after treatment the 

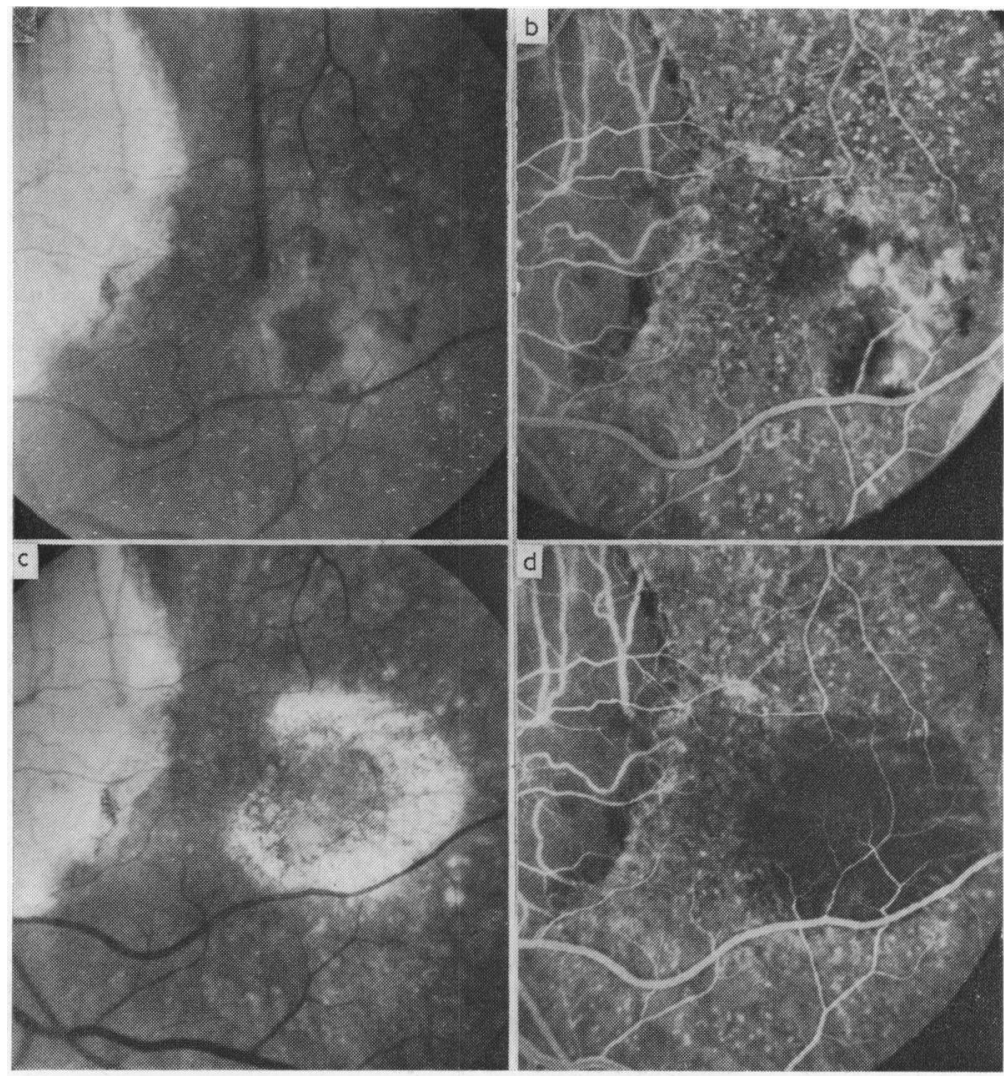

Fig. 3 Case 6. A 71-year-old man, whose previous left eye disciform lesion had been successfully treated by argon laser photocoagulation 3 years before, had recurrence of the symptoms due to a new disciform lesion (3a) with neovascular tissue below and temporal to the fovea (3b). Six weeks later there was profound atrophy of the pigment epithelium and choriocapillaris $(3 \mathrm{c}, \mathrm{d})$

lesions produced by the krypton laser differed from those following argon laser photocoagulation in some respects. The dark appearance during the first 2 weeks after therapy occurs with both lasers and can be ascribed to the masking effect of the swollen retinal pigment epithelium. The persistence of the darkness after this time, when the swelling had resolved, is likely to be due to confluent closure of the choriocapillaris. This impression is supported by the observation of well demarcated atrophy of the pigment epithelium within 6 weeks of photocoagulation and the observation of large choroidal vessels within the lesion during angiography. It is our impression that choroidal closure is more complete and seen more consistently after krypton than after argon laser photocoagulation. This impression is in accord with histopathological observations (Marshall and Bird, 1979). If as high a proportion as $85 \%$ of krypton energy passes into the choroid, this tissue may represent the site of maximum energy absorption. The effect of multifocal absorption by the choroidal melanosomes as opposed to the continuous absorption by the melanin in the apical portion of the retinal pigment epithelial cells was not apparent. The high energy density of absorption which might be expected by the choroidal melanosome would predictably give rise to haemorrhages due to blood vessel wall necrosis (Marshall and Bird, 1979), but this was not observed in these patients. However, the number of cases observed was small, and in a larger sample this complication might become apparent. Within the lesions observed the choroidal closure was complete, suggesting that the effect of the absorbed energy was similar to that which might be seen had the choroid been a continuous absorbing medium.

The clinical effect of the greater energy uptake in the choroid by krypton laser energy and more consistent choroidal vessel closure is difficult to predict. It could be argued that occlusion of choroidal blood vessels from which the abnormal neovascular tissue is derived may give rise to a greater cure rate, but may infarct pigment epithelium and receptors outside the irradiated area.

The success rate and visual outcome using krypton cannot be compared with that of argon with such a small sample. However, it is clear that disciform lesions can be treated successfully with the krypton 
laser with good visual results even if the neovascular tissue approaches close to the fovea. The relative merits of the 2 lasers as therapeutic agents can be assessed only by controlled clinical trial. If the trials which are under way at present show that there is any benefit derived by the treatment of disciform lesions by argon laser photocoagulation, a trial to compare the 2 modalities would be justified.

We express our gratitude to Lasertek for lending us their krypton laser which allowed us to undertake this study. I would also like to thank Miss J. Bramley for secretarial assistance and Mr K. Sehmi for photographic expertise.

\section{References}

Bird, A. C. (1974). Recent advances in the treatment of senile disciform macular degeneration by photocoagulation. British Journal of Ophthalmology, 58, 367-376.
Gass, J. D. M. (1971). Photocoagulation of macular lesions. Transactions of the American Academy of Ophthalmology and Otolaryngology, 75, 581-608.

Gass, J. D. M. (1973). Drusen and disciform macular detachment and degeneration. Archives of Ophthalmology, 90, 206-217.

Gregor, Z., Bird, A. C., and Chisholm, I. H. (1977). Senile disciform macular degeneration in the second eye. British Journal of Ophthalmology, 61, 141-147.

Marshall, J., and Bird, A. C. (1979). A comparison of argon and krypton laser lesions of the retina. British Journal of Ophthalmology, 63, 657-668.

Marshall, J., Hamilton, A. M., and Bird, A. C. (1974). The intraretinal absorption of argon laser irradiation in human and monkey retinae. Experientia, 30, 1335-1337.

Marshall, J., Hamilton, A. M., and Bird, A. C. (1975). Histopathology of ruby and argon laser lesions in monkey and human retina: a comparative study. British Journal of Ophthalmology, 59, 610-630.

Schatz, H., and Patz, A. (1973). Exudative senile maculopathy: 1. Results of argon laser treatment. Archives of Ophthalmology, 90, 183-196. 